Proceedings of the 50th Hawaii International Conference on System Sciences | 2017

Proceedings of the $50^{\text {th }}$ Hawaii International Conference on System Sciences (HICSS) - 2017

\title{
Understanding ICT in ICT4D: An Affordance Perspective
}

\author{
Devinder Thapa \\ University of Agder \\ Kristiansand, Norway \\ devinder.thapa@uia.no
}

\author{
Mathias Hatakka \\ Dalarna University \\ Borlänge, Sweden \\ mht@du.se
}

\begin{abstract}
Understanding the role of ICT for development is at the core of ICT4D research. However, prevailing research in this field most often focuses on access or readiness of a technology, or on the outcomes of the technology use. Less attention has been paid to understand the mechanism of the technology use that leads to the outcomes. The question of why ICT in a development context sometimes work and sometimes does not work still remains a subject of enquiry. To enhance our understanding in this regard, we propose to use the concept of affordances to unfold the "black boxed" nature of ICT. We revisited a case from Kenya to illustrate the application of affordances in a ICT4D context. The findings show that the benefits of ICT can be harnessed only if the users in the underprivileged communities can perceive and actualize the affordances of the ICT. However, what is ICT affordances, and how people perceive and actualize the affordances in the context of developing countries are the issues that we delve in this paper.
\end{abstract}

Keyword: ICT4D, Affordances, Developing Countries, Education

\section{Introduction}

In 2012 Walsham encouraged the field of Information System to broaden the perspective by focusing on how to "use ICTs to help make a better world, where everybody has the opportunity and capability to use technologies to make better lives for themselves"[1]. Hence, the quest in information and communication technologies for development (ICT4D) research and practice is twofold. First, to understand the role of ICT in development and second, to understand what development entails. Independently both terms have been well defined.
ICT is understood as digital technologies with certain properties, features and functionalities. Development has mainly been understood as human development in recent ICT4D literatures. To be more specific, capability approach in this context [2]. The capability approach focuses on enabling or enhancing freedom of choice where commodities (for instance ICT) play an instrumental role. The challenge, however, is to understand the process by which ICT develop or expand individuals opportunities [3, 4]. Researchers argue to give appropriate account of both ICT and the ' $\mathrm{D}$ ' in explaining ICT4D $[4,5]$. Social theories such as actor-network theory, social capital and structuration theory are suggested to be able to describe the sociotechnical nature of the ICT4D phenomenon [6-8]. These theories are useful in providing macro level description. However, these theories do not explain the mechanism of ICT use and effect in details, and ICT still remains as a "black box". The same can be said for research using the capability approach, where ICT often are regarded as neutral and as a commodity just like any other [9]. The question of why the same ICT with similar functionalities sometimes works and sometimes does not work still remains unanswered. The gap in design of ICT artifact and its use in real contexts are seen as one of the explanations [10]. However, how this gap arises and how can we reduce that gap needs deeper understanding of the process of ICT use and the actors' role in the process.

One tenable argument can be that people do not use technology if they do not perceive any possibilities of action (or benefits) from it [11]. Following this argument, we propose that use of affordances from ecological psychology can provide a lens to understand the process of ICT in ICT4D, so as to better understand how ICT can lead to development. The aim of the study is to illustrate how affordances can enhance our understanding of the mechanism by which ICT enable or constraint 
possibilities and opportunities for individuals and groups.

In Information Systems research, affordances is defined as "the possibilities for goal-directed action afforded to specified user groups by technical objects"[12]. The action possibilities are dependent on the relationship between systems and goaloriented users in the context in which the information systems are used [11]. The concept has been applied to understand the IT-associated change process in organizational setup $[13,14]$. In this paper, we take a similar approach, however on a societal level. The societal context is more challenging to research because of its complex social, political, cultural and environmental configurations. We present a case of study circles in rural Kenya to understand how affordances are perceived and actualized in marginalized communities.

The next section describes the concept of affordances in detail followed by research approach. Thereafter, we present a case study from Kenya to illustrate how the concept of affordances can be used to unfold the 'black box' nature of ICT in ICT4D. Finally, we conclude the paper with a discussion and future directions.

\section{Theoretical Premises}

The concept of affordances goes back to the work of perceptual psychologist James J. Gibson. In his article The Theory of Affordances [15], he proposed that "The affordances of the environment are what it offers the animal, what it provides or furnishes, either for good or ill. (pp. 127)" He went on to argue that inherent values and meanings of things in the environment can be directly perceived, and this information can be linked to the action possibilities offered to the organism by the environment. Affordances, however, are neither the properties of the environment nor the characteristics of the individual [16]. Instead, affordances are relative to the characteristics of individuals, such as their physical dimensions and abilities, social needs and personal intentions, and the features of the environment [17]. In other words, affordances are neither an outcome of the artifact alone nor the actor alone, but of the interaction between the actor and the artifact [18].

The concept of affordances has been debated on its relational ontology [19]. The ontological differences in affordances are due to two contradicting perspectives: design vs use [19]. The relational ontology from the design perspective claims that affordances can be designed [20]. For example, while the designers' design any IT artifact, they keep a virtual user in their mind, though the context might be blurry [17]. Therefore, the affordances exist independent of the user, but it has an impact only if the user perceives and actualizes it. On the other hand, from the use perspective the relational ontology suggests that affordances emerge in practice in a particular context [21]. Therefore, it is not possible to label a priori attributes as affordances of entities.

We agree with both perspectives, however reluctant to take side of any particular one. Rather, we derive our ontological base from the critical realism perspective $[22,23]$. The main idea behind Bhasker's critical realism [24] is stratification of the reality in three domains: real, actual and empirical. the real domain consists of structures of objects, both physical and social, with capacities for behavior called mechanisms [25]. This mechanism may (or may not) trigger events in the domain of the actual. In the empirical domain the events triggered in the actual domain may (or may not) be observed. Thus, structures are not deterministic, they have the potential to enable and constrain events through inherent mechanisms. In other words, "from a critical realism perspective, understanding the organizational effects/outcomes associated with introducing new structures (e.g. new information systems) and how they occur can be viewed as understanding the generative mechanism associated with those structures" [26].

From the critical realism perspective, affordances arises from the relation between a structure or object and a goal directed actor or actors. In information systems, critical realism define affordance as "the potential for behaviors associated with achieving an immediate concrete outcome and arising from the relation between the object (e.g. IT artifact) and a goal-oriented actor or actors" [23]. While an affordance itself is an everpresent potential for action, the details of its actualization in a specific instance are contingent on aspects of the techno-organizational context and thus the outcome is indeterminate. The context gives rise to a variety of mechanisms that may act as conditions that initially enable or constrain the actualization of the affordance, or that later stimulate its actualization in a variety of ways, or release constraints.

Thus, affordances are a type or subset of generative mechanisms [22]. In a macro level, the generative mechanism may arise from structures alone, and their causal powers triggered without the intervention of an actor. When the object of study is information technology, and the question relates to how the introduction of that technology affects an 
organization, the more focused nature of the affordance concept is suggested. Affordance exists at what critical realists refer to as the domain of real. Someone who is capable of performing the actualization must exist for the affordance to have any meaning, but that person need not be identified. The affordance will not be actualized (brought into the domain of the actual) unless there exist someone who in addition to having the necessary capability also has an intention or goal that is served actualizing the affordance [16].

In this definition four aspects of affordances are highlighted: their status as the potential for action rather than the action itself, their relational aspect, their connection to an immediate concrete outcome resulting from goal-directed behaviors, and their application at multiple levels. From the three layers of critical realism the affordances can be categorized as possessed but unexercised, exercised but unactualized (or partly actualized), and actualized but not necessarily empirically observed. To extend this categorization, we adopted Gaver [27] framework in which the affordances has been classified according to the availability of affordances and perceptual information (Figure 1).

Gaver [27] suggested four dimensions: Perceptible affordances, in which there is perceptual information available for an existing affordance. Hidden affordances, if there is no information available for an existing affordance, it is hidden and must be inferred from other evidence. False affordances, if information suggests a non-existent affordance, a false affordance exists upon which people may mistakenly try to act. Correct rejection, people will usually not think of a given action when there is no affordance for it or any perceptual information suggesting it.

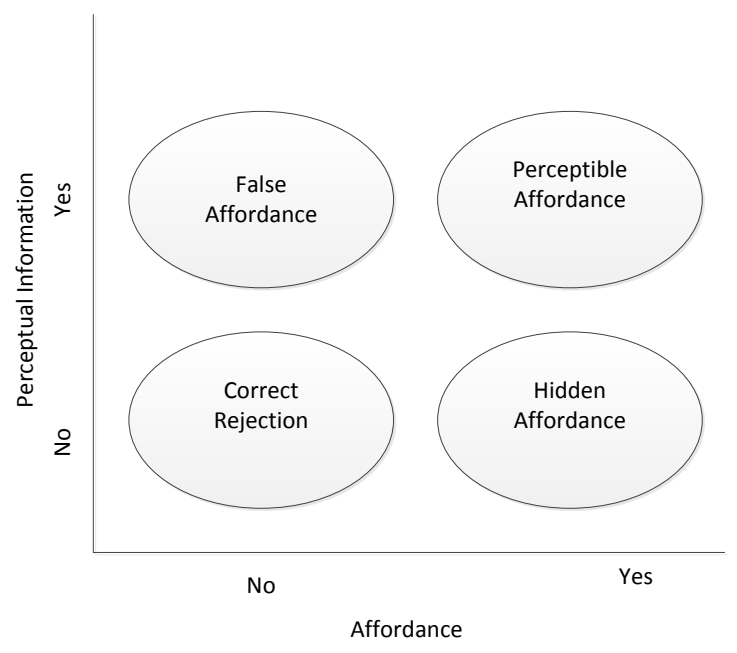

Figure 1. Types of affordances (Gaver, [27])
The case description and analysis sections describe the application of this theoretical framework with the aim of unfolding the nature of ICT in ICT4D context.

\section{Research Approach}

In this paper, based on the critical realism perspective, we illustrate how affordances can enhance our understanding of the mechanism by which ICT enable or constraint possibilities and opportunities for individuals and groups. This is done by reanalyzing a case study about ICT supported study circle education in Kenya that previously have been published using the capability approach as the analytical lens (see for example [28-30]). The data were collected during two field trips to the Kenyan south coast in 2012 (in May and October). The data were collected using group interviews with 15 study circle groups (109 study circle members). Each interview lasted for around 1 hour. All interviews were semi-structured using an interview guide that was designed based on the capability approach. However, the data fits well with the affordance perspective, since questions were asked about reasons for use/non-use of ICT, students' expectations, skills and goals. The questions asked followed 5 themes:

1) Their opinion about the study circle education.

2) How ICT was used in the groups.

3) The value of ICT in the study circle groups.

4) Restricting factors for ICT use and their study circle participation.

5) Enabling factors for ICT use and their study circle participation.

The reanalysis of the data for this paper was based on Gavers' [27] framework. All the interviews had previously been transcribed and we started the analysis by looking for statements where the participants talked about affordances with the technology. For example, if one of the participants talked about the benefits of using the computers to start a small internet café, the statement indicated that they perceived an affordance with the computers. All the statements about affordances were, thereafter, categorized based on Gravers 4 division of affordances. For example, if the ICT supported an affordance and the participants had the information and skills required to achieve it, it was categorized as a perceptible affordance. If the affordance were not supported by the ICT, it was categorized as a false affordance. After the first broad categorization, we went through each category again and looked for 
patterns in the data. For example, in the category of perceptible affordances we found some evidences such as the groups used the technology to start small internet cafés, and they used Internet to look for information to help them in their income generating projects. The results presented in the paper are the most common patterns found in the data. The subsequent section describes the case analysis in detail.

\section{Case Description and Analysis}

The case analyzed in this paper involves an educational project that was initialized and run by Coastal Oceans Research and Development-Indian Ocean (CORDIO), an organization that is concerned with capacity building for rural people in Kenya's coastal regions. The aim of the project was to address the educational needs of the rural poor so as to support their livelihood and income-generating activities [31]. The education was based on the Swedish "folkbildnings" concept, which is a participatory form of education that is organized in study circles. The study circles facilitate the participants to learn a variety of skills in a selfsustained manner. While the focus of the project was on income-generating activities, the project also aimed to teach basic skills, such as reading and writing, numeracy, IT-literacy and subject specific topics using ICT. The groups had different topics that they studied, and based on the topics, different instructors visited the groups to teach the skills needed. For example, instructors from CORDIO were teaching basic computer skills, private companies such as m-Pesa were teaching mobile services and government officers were teaching agricultural and fishery skills. The groups also had different projects, such as soap and coconut oil production and ecotourism, that was supported by CORDIO [32].

The main objectives of the project were:

- to introduce ICTs into poverty alleviation activities in order to support environmentally sustainable livelihoods,

- to introduce adult education that follows the Swedish "folkbildning" concept of self-help groups and activities to empower rural villagers,

- to alleviate poverty and increase the standard of living by introducing alternative livelihoods, and

- to develop collaboration between project partners in support of poverty alleviation, in order to reduce the economic vulnerability of coastal communities of the Kenyan south coast. [33]

The study circle groups were provided with Internet, computers, and printers. Most of the groups were given one or two desktop computers, except two groups who also received two laptops (XO computers). The introduction of ICT had three main purposes: i) to support the education with learning resources, ii) to provide the study circle groups access to computers in areas where computers were not readily available, and iii) to increase ICT literacy among the participants through ICT training.

\subsection{Case Analysis}

The analysis from the case is presented according to Gavers [27] four dimensions of affordances i.e. perceptible, false, hidden and correct rejection.

\section{Perceptible Affordances}

The affordances that the study circle participants perceived with the technology differed between the groups. However, all of them mainly perceived uses with the technology that could help them to make an income. The participants live in poor conditions and their time was very valuable to them, and the activities had to be of benefit for their livelihood. This is related to seeing the participants as goal oriented actors where they perceive affordances in accordance to their goals, i.e., the goals they had with the technology use was to increase their family income.

The participants in the study circle groups mainly relied on income from agriculture or fishery. By getting access to computers, printers, and Internet they, hence, looked for uses to support their income generating activities. For example, some groups used the computers and Internet to find information to increase their skills and understanding about different crops. For example, one of the villagers stated:

\section{"By using ICT when we are talking about a particular crop we can use the facility on the ICT to find more information about that particular crop, to benefit and get access to more information.",}

Such uses of course required that the participants had both the technologies required (computer or mobile phone with an Internet connection) and the information literacy required to find the information. During the interviews it was clear that the information literacy among the majority of the participants was low. However, due to the structure 
of the study circle education, it could be enough if one member possessed the skills needed since she or he could aid those that did not have the required skills. The example shows that the perceptible affordances arise not only between ICT and individual actor, but it also can arise between ICT and collective actors. Two interview quotes illustrate this:

SC participant 1: "We manage; I know how to search for that. But I am the only one."

SC participant 2 "Yes, he help us very much because he know how to. Yes, we can learn from each other."

The groups also perceived affordances with the technology to support their side-projects. In addition to the main income generating activities for the groups, most of them also had other projects to help them generate an income. The case also supports Gaver's [28] notion of sequential affordances, in which, one affordance leads to another affordance. For example, one group made soaps that they sold to a local hotel, several groups had a tourist camp for eco-friendly tourism and one group had water purifying station and a fish farm. The ICT use to support those activities varied depending on the nature of the project, but most could, for example, see that they could use the technology and Internet to market their projects in different ways. The ecotourism groups used Internet to communicate with potential customers, the group that made soap use a printer to print labels for their products. However, the uses were not accessible to all groups due to either technical restraint (such as lack of Internet) or lack of personal skills.

The above mentioned activities are uses that were intended by the project, where the use of ICT mainly was to support their existing projects in addition to teaching the study circle participants basic computer skills. However, most of the groups also perceived that they could make an income from the technology in itself, by letting the rest of the communities use the computers, printers and/or Internet for a small fee. The use of computers for making an income was not something that was intended by the project from the start, however when it had started, income generation activities were encouraged and also supported by the project organization. This, again, shows how the actors perceive affordances with the technology that can help them to fulfill the goals that they have (and in this instance, the goal to make an income to sustain a livelihood and increase wellbeing). One interview participant told us as follows.
"Right now from the income side they use the computers as a source of income. Some of the students that started the computer program finished the period and some didn't. Some of them could not pay the small fee that we had to impose for them to get the training. [...] They had to pay 200 for registration and then 200 per month." and "With the computer they must pay because there is printing and if you go to Internet you have to pay. That's how you can make some money if you have a computer.

Just because an affordance is perceptible it does not, however, automatically lead to actualization of the affordance. For example, sometimes group members could perceive uses (or action possibilities) of the technology but their social conditions prevent them to actualize those possibilities. In this case, many of the groups were bounded by strict cultural norms that effected most parts of their lives. For example, one of the women groups, perceived several benefits from accessing information on the Internet, such as agricultural information, information about women rights and information about the Kenyan constitution. Even though the women could perceive the affordance and the material properties supported the use (the group had Internet access on their computers), the group could not realize it due to constraining social norms. As one village woman stated:

"The problem of accessing Internet for a woman, like where we are in [the village of the group] the ladies are not allowed to browse [Internet] for her husband".

This example shows that if development opportunities for the individuals should be available it is not enough that the technology support it and that the individuals can perceive it. Socio-cultural conditions must also be enabling otherwise the development process will be halted before the individuals can actualize the affordances.

\section{Hidden Affordances}

Most of the participants in the study circles had never used a computer before the project was introduced. Hence, their knowledge of what could be done with computers and Internet was limited. In the analysis, we found examples of uses that was intended by the project but remained hidden for some of the groups. One example is the use of learning resources. The groups with XO computers had learning resources that were easily available to them, since the resources were pre-installed in the 
computers, and they could see the benefit of using them. One interviewee stated:

\begin{abstract}
"It was helpful [the pre-installed learning resources]. The environment was especially for marine issues so we could see what was in the content and compare that to the actual life and see that there was some truth in the content and we could trust it."
\end{abstract}

However, most of the groups with stationary computers had only standard software installed (for example, windows and the office package). Although the learning content was available to the groups through Internet, it was not pre-installed. Therefore, the group members either did not know about the resources, or had difficulties in finding it. The reasons were low computer skills and low information literacy skills. To make it easier to find all content, CORDIO was developing a learning platform where the groups could easily access the contents. However, the affordance remained hidden for the group members until the platform was completed, and they got training in access and use of the resources.

The case also revealed that the low IT literacy skills of trainers can also influence the ability of the users in perceiving the ICT affordances. For example, all groups had a computer trainer, however, the skill of the trainer varied greatly between the groups. Some groups had teachers from CORDIO or other organizations visiting them and the teachers could then, not only tell them about the possibilities of the technology, but also teach them the skills needed to utilize it. For example, one of the women groups were taught how to use their mobile phones to transfer money by representatives from m-Pesa. Once they had learned about the service, it was appreciated by the women. However, in many groups the teacher was one of the group members who had very limited computer skills. During an interview one participant expressed her discontent:

"The teachers have no proper computer training and she [the teacher] learned from the other person before her. The teachers had only few skills so the problem I face is that I only learn the skills that she has."

In these instances, the affordances that the group members could perceive with the computers were limited by the teacher's knowledge. ICT uses that could potentially benefit the group remained hidden because of the limited skill of the teacher.

\section{False Affordances}

As previously mentioned, many of the groups used the computers, printers, and Internet to try and make an income by letting the communities use the technology for a fee. To some degree it was successful and the groups could make a small income from their services. However, for some groups it was a false affordance, because the groups' expectations were higher than what the technology could afford. The groups were expecting to make an income when the ICT properties did not allow it. For example, lack of Internet access restricted the number and usefulness of the services offered, or the high cost for stationaries meant that the community members would not be able to pay the fee needed to sustain it. In this regard, one entrepreneur stated:

\section{"To offer printing was not a good business model since there were many high costs, and even the stationaries. We would have to have a proper printing machine so that you could make it into the commercial side of it. The printing machine we have is not worthwhile for business. It was a lot of frustration."}

Based on the case analysis, we identified two ways to convert the false affordance into perceptible affordances: by making changes to the material properties so as to make the technology support the affordance they perceive, or by changing the expectation that the individuals have on the use. For example, in the situation mentioned earlier it could be by providing the groups with mobile Internet or satellite Internet (where access is available), or by providing the groups with printers that have a lower cost per printed page and so on. Sometimes the groups asked for different kind of printers, but there was no budget for providing the groups with new printers. In this situation, the users' expectations could also be changed, and make them offer services that were already available. For example, two groups offered computer lessons in addition to other services, which only required a computer and someone skilled enough to teach basic computer skills.

Another, similar, example is where the groups wanted to use Internet to market their projects but did not have access to Internet. They could see the use, but the material properties did not support it.

\section{Correct rejection}

The most difficult category of affordance to find in our data is correct rejection. However, we present one instance in which one of the women groups chose to focus on mobile phones instead of 
computers. This meant that they rejected many of the potential benefits that computers could afford. For example, when using a mobile phone it was difficult to acquire services such as access to learning resources, providing community services and so on. The correctness of the rejection of the computers was due to several factors, for example, the group did not have anyone with computer skills, and they did not have anywhere to store a computer (their meeting was held in an outdoor public place just outside their village). Hence, even if they would have perceived benefits with a computer it would have been difficult for them to use it.

\section{Discussions}

We started this paper by questioning how ICT in ICT4D can be understood. For example, why ICT in a development context sometimes work and sometimes does not work. It has been argued that people do not use a technology if they do not see any action possibilities to achieve their goals [11]. But what is 'action possibilities'? And how do people perceive and actualize it? To enhance our understanding in this regard, we proposed to use the concept of affordances to unfold the "black boxed" nature of ICT. We also argue that critical realism can provide better ontological foundation to affordances for ICT4D researcher by synthesizing the design and use perspective.

In our analysis, we have extended the Gaver's framework [28] to a societal level, by explaining how different socio-cultural factors affect the perception and actualization of affordances. For example, the case analysis show that when the villagers perceived the possibilities of technology for income generating activities and also acquired correct information, they were able to realize those affordances. On the other hand, the case also shows how cultural norms prevented some women in the actualization of a perceptible affordance. Gaver's framework does not account for sociocultural factors and we suggest considering these factors while applying affordances concept in ICT4D context. Likewise, Gaver's framework disregards the affordances that can emerge in practice without having prior information. In our case we identified some instances where the affordances were emerged in practice. However, the Gaver's framework provided useful guidelines in illustrating why some affordances sometimes remain hidden or can be false as well.

In the paper we also suggest that the theory of affordances is relevant in explaining the ICT in the ICT4D context. It can help to bridge the designreality gap by providing guidelines to designers in explaining how users appropriate the technology in practice. The identification of perceptible affordances can be a common ground for both designers and users to bridge the gap.

The term affordances in the context of ICT4D has recently started to appear in some studies [21, 34, 35], these studies however focused on use of affordances concepts in analyzing the case. In this paper, we further advocate to apply the theory of affordances in understanding ICT. . For example, the analysis in this paper shows that the same affordance could be perceptible, hidden or false for different groups in a particular context. In other words, it is relative within a community and we cannot claim that certain affordances are hidden or false for everyone. For example, in regards to using the technology to make an income, for some groups the affordance were perceptible, whereas for other it was hidden (when the ICT skills of the teacher where low) or false (where the ICT properties did not support the users expectations).

Furthermore, the study highlights some implications to practice by informing designers and developers about the need to understand how people perceive and actualize affordances. This can inform practitioners about properties that can be incorporated into ICT artifacts. However, as can be seen from our case analysis, they should be also aware that affordances can be appropriated in the way that was not intended by the project. By using the theory of affordance in our analysis we can find unintended (not necessarily meant as a negative) uses and consequences that are a result of goal oriented actors' appropriation of the affordances that are available to them. In addition, if the users of the technology lack necessary information it may lead to false or hidden affordances in the same community between different groups. Therefore, efforts should be made to provide a shared understanding of the action possibilities of the technology. The identification of the affordances can happen on an individual- as well as a collective level. The abilities of the trainers are also helpful in informing the users about hidden and false affordances, at the same time training programs can help to reveal the affordances before the users rejects ICT use.

We previously mentioned that the prevailing human development perspective in ICT4D to a large extent is based on the capability approach. And we argue that a capability approach analysis would also benefit from incorporating the aspect of affordances in the analysis. For example, the most used operationalization of the capability approach in ICT4D research is Kleine's choice framework [3638]. We argue that the theory of affordances can 
complement the Kleine's framework in explaining how structure and agency enable generative mechanism that leads to enhanced capabilities. Kleine's choice framework has paved the way for further enquiry to understand the mechanism by which ICT leads to enablement of capabilities and functionings. As Kleine [35] mentioned, the framework is a 'living tool' and suggested to improve it further. The addition of affordances lens would provide better explanation on how ICT enable individual/collective capabilities/functionings. In the existing framework, ICT has been mainly analyzed for its affordability, accessibility and availability. These preconditions are necessary to enable the possibilities of action or 'affordances' in this context, however the enablement of the capabilities/functionings depends on the perception and actualization of the existing affordances [16, 39, 40]. In our future endeavor, we will integrate Kleine's choice framework and affordances theory to explain the mechanism by which perception and actualization of ICT affordances leads to an increase in individuals' choices, capabilities and functionings.

\section{Conclusion}

In this paper, we proposed the use of affordances to enhance the understanding of ICT in ICT4D. In doing so, we argued that the theory of affordances is a relevant lens to understand the mechanism of ICT use and effects in developing countries context. To strengthen our argument, we reanalyzed a case from Kenya about ICT use in study circle educations. The empirical case shows that people perceive action possibilities from ICT rather than analyzing their properties. The idea we gained through this study is that it is needed to understand what action possibilities people are looking for in a technology. Likewise, dissemination of proper information (individually or socially) is important to make the affordances perceptible, otherwise the affordances can be hidden or false or sometimes rejected without understanding the use.

\section{References}

1. Walsham, G., Are we making a better world with ICTs\&quest; Reflections on a future agenda for the IS field. Journal of Information Technology, 2012. 27(2): p. 87-93.

2. Sen, A., Development as Freedom. 2000, Oxford: Oxford University Press, UK.
3. Hatakka, M., The Capability Approach in ICT4D Research, in Örebro University Business School. 2013, Örebro University: Örebro. p. 195.

4. Thapa, D. and Ø. Sæbø, Exploring the link between ICT and development in the context of developing countries: A literature review. Electronic Journal of Information Systems in Developing Countries, 2014. 64: p. 1-15.

5. Burrell, J. and K. Toyama, What constitutes good ICTD research? Information Technologies \& International Development, 2009. 5(3): p. pp. 82-94.

6. Walsham, G. and S. Sahay, GIS for DistrictLevel Administration in India: Problems and Opportunities. MIS Quarterly, 1999. 23(1): p. 39-65.

7. Thapa, D., M.K. Sein, and $\varnothing$. Sæbø, Building collective capabilities through ICT in a mountain region of Nepal: where social capital leads to collective action. Information Technology for Development, 2012. 18(1): p. 5-22.

8. Díaz Andrade, A. and C. Urquhart, The value of extended networks:Social Capital in an ICT intervention in rural Peru. Information Technology for Development, 2009. 15(2): p. 108-132.

9. Zheng, Y. and B.C. Stahl, Technology, Capabilities and Critical Perspectives: What can Critical Theory Contribute to Sen's Capability Approach? Ethics and Information Technology, 2011. 13(2): p. 69-80.

10. Heeks, R., Information systems and developing countries : Failure, success, and local improvisations. The Information Society, 2002. 18(2): p. 101-112.

11. Leonardi, P.M., When flexible routines meet flexible technologies: Affordance, constraint, and the imbrication of human and material agencies. MIS quarterly, 2011. 35(1): p. 147-167.

12. Majchrzak, A. and M.L. Markus, Technology affordances and constraints in management information systems (MIS). Encyclopedia of Management Theory,(Ed: E. Kessler), Sage Publications, Forthcoming, 2012.

13. Strong, D.M., et al., A theory of organization-EHR affordance actualization. Journal of the Association for Information Systems, 2014. 15(2): p. 53.

14. Seidel, S., J.C. Recker, and J. Vom Brocke, Sensemaking and sustainable practicing: functional affordances of information systems in green transformations. Management Information Systems Quarterly, 2013. 37(4): p. 1275-1299.

15. Gibson, J.J., The Ecological Approach to Visual Perception. 1979: Boston: Houghton-Mifflin.

16. Stoffregen, T.A., Affordances as properties of the animal-environment system. Ecological Psychology, 2003. 15(2): p. 115-134. 
17. Chemero, A., An outline of a theory of affordances. Ecological psychology, 2003. 15(2): p. 181-195.

18. Van Osch, W. and O. Mendelson, A typology of affordances: Untangling sociomaterial interactions through video analysis. 2011.

19. Stendal, K., D. Thapa, and A. Lanamäki. Analyzing the Concept of Affordances in Information Systems. in 2016 49th Hawaii International Conference on System Sciences (HICSS). 2016. IEEE.

20. Norman, D.A., The psychology of everyday things. 1988: Basic books.

21. Zheng, Y. and A. Yu, Affordances of social media in collective action: the case of Free Lunch for Children in China. Information Systems Journal, 2016.

22. Bygstad, B., B.E. Munkvold, and O. Volkoff, Identifying generative mechanisms through affordances: a framework for critical realist data analysis. Journal of Information Technology, 2015.

23. Volkoff, O. and D.M. Strong, Critical Realism and Affordances: Theorizing IT-Associated Organizational Change Processes. Mis Quarterly, 2013. 37(3): p. 819-834.

24. Bashkar, R., A realist theory of science. A Realist Theory of Science, 1975.

25. Dobson, P.J., The philosophy of critical realism-an opportunity for information systems research. Information Systems Frontiers, 2001. 3(2): p. 199-210.

26. Mutch, A., Technology, organization, and structure-a morphogenetic approach. Organization Science, 2010. 21(2): p. 507-520.

27. Gaver, W.W. Technology affordances. in Proceedings of the SIGCHI conference on Human factors in computing systems. 1991. ACM.

28. Ater, S. and M. Hatakka, Study Circle Outcomes: An Evaluation of an Adult Education, ICT and Livelihood Project Among Sel-Help Groups, in ICT for Anti-Corruption, Democracy and Education in East Africa, K. Sarajeva, Editor. 2013, Spider: Stockholm. p. 83-95.

29. Hatakka, M., et al. Back to Basics - Why (Some) ICT4D Projects Still Struggle in 12th International Conference on Social Implications of Computers in Developing Countries (IFIP wg9.4). . 2013. Ocho Rios, Jamaica.

30. Hatakka, M., et al., Capability Outcomes from Educational and ICT Capability Inputs - An Analysis of ICT Use in Informal Education in Kenya. The Electronic Journal for Information Systems in Developing Countries, 2014. 61(1): p. 1-17.

31. SPIDER. Education for sustainability Study circles, ICTs and the youth. 2012 October 28,
2012]; Available from: http://www.spidercenter.org/projects/educationsustainability---study-circles-icts-and-youth. 32. CORDIO, Empowering Self-Help groups in Kenya Through ICT for Better Education and Alternative Livelihood Activities. 2010, CORDIO: Mombasa.

33. Wamala, C., Empowering Self-help Groups in Kenya and India Trough ICT, in Empowering Women Through ICT, SPIDER, Editor. 2012, SPIDER: Stockholm. p. 31-36.

34. Andrade, A.D. and B. Doolin. Affordances and agentic orientations: An examination of ICT4D users. in Proceedings of SIG GlobDev Sixth Annual Workshop. 2013. Citeseer.

35. Turmo, M.P., E.A. Castañ, and À. Guijosa, Using the affordances of wiki to support collaborative argumentation in secondary science education. Secondary Education in the 21st Century, 2010: p. 1-56.

36. Kleine, D., ICT4WHAT? - Using the Choice Framework to Operationalise the Capability Approach to Development. Journal of International Development, 2010. 22(5): p. 674-692.

37. Kleine, D., The Capability Approach and the 'Medium of Choice': Steps Towards Conceptualising Information and Communication Technologies for Development. Ethics and Information Technology, 2011. 13(2): p. 119-130.

38. Kleine, D., Technologies of choice?: ICTs, development, and the capabilities approach. 2013, Cambridge, MA: MIT Press.

39. Bernhard, E., J.C. Recker, and A. BurtonJones, Understanding the actualization of affordances: A study in the process modeling context. 2013.

40. Zammuto, R.F., et al., Information technology and the changing fabric of organization. Organization Science, 2007. 18(5): p. 749-762. 